\title{
Erratum to: An Impure Logic of Representational Grounding
}

\author{
Fabrice Correia ${ }^{1}$
}

Published online: 20 April 2017

(c) Springer Science+Business Media Dordrecht 2017

\section{Erratum to: J Philos Logic DOI 10.1007/s10992-017-9435-0}

The original version of this article unfortunately contains mistakes introduced during the publishing process. The mistakes and corrections are described in the following list:

1) Footnotes 1 and 2 were incorrectly assigned. The first two footnotes found on the first page should be footnote 1 and 2 respectively. Citation of these footnotes is found in the first paragraph of the main text. The subsequent footnotes are re-numbered accordingly.

2) There was an incorrect renumbering and internal referencing of the Definitions, Facts, Propositions and Theorems.

The original article was corrected.

The online version of the original article can be found at http://dx.doi.org/10.1007/s10992-016-9409-7.

Fabrice Correia

fabrice.correia@unine.ch

1 Institut de Philosophie, Université de Neuchâtel, Espace Louis-Agassiz 1, 2000 Neuchâtel, Switzerland 